Another display showed something of the researches of the Association on the possibilities of wind-power for electricity generation on different scales of use. A survey, for which several new measuring instruments have been developed, is in progress in western coastal areas of Great Britain and Ireland. Many specially favourable sites have been found, and pilot plants, of $100-\mathrm{kW}$. capacity, are being built in Orkney and for another site. The performance will be tested as a guide to the design of larger machines for which a basis has already been formed by comprehensive design and costing studies. At the same time, the study includes the design, development and use of smaller plants adapted to typical isolated communities in Britain and abroad where adequate alternative sources of power are difficult to come by. For topical interest, the actual record was displayed of the highest wind-speed yet recorded in the British Isles, namely, 125 m.p.h. on Costa Hill, Orkney, early this year.

\section{LATTICE DEFECTS AND THE ELECTRICAL RESISTIVITY OF METALS}

$\mathrm{A}^{\mathrm{s}}$ $\mathrm{N}$ informal conference arranged by the Department of Metallurgy, University of Birmingham, and concerned with recent work on the influences of deformation and irradiation on the electrical properties of metals, was held in Birmingham during April 24-25.

Following an introductory survey by $\mathrm{T}$. Broom (Birmingham), which served to enumerate some present-day problems, J. A. Manintveld (Delft) presented new results for the recovery of resistivity of pure metals after heavy deformation at low temperatures. There is general agreement that a welldefined recovery process occurring at around $0^{\circ} \mathrm{C}$. is due to the movement of single vacancies; but a satisfactory account of recovery at lower temperatures is lacking. Prof. M. J. Druyvesteyn (Delft) discussed possible processes for this and also gave results of an investigation into recovery of mechanical properties of polycrystalline wires after low-temperature deformation.

Various mechanisms for the generation of vacancies and interstitial ions during deformation were critically reviewed by Prof. N. F. Mott (Bristol), and one of these, the intersection of screw dislocations, was used by $H$. G. van Bueren (Eindhoven) as a basis for a theoretical treatment of resistivity-extension curves in which a three-halves power law is obeyed. $P$. Jongenburger (Eindhoven) completed the discussion of vacancy effects in pure metals by describing his calculations of scattering due to single vacancies in copper, silver and gold.

A new theoretical treatment by S. C. Hunter and Dr. F. R. N. Nabarro (Birmingham) of the resistance due to screw and edge dislocations in metals was presented and the need for a calculation of scattering from stacking faults was pointed out. Predictions of anisotropic scattering from single dislocations formed the basis of an account given by C. W. Berghout (Delft) of some experiments on the anisotropy of resistivity of plastically stretched foils. J. F. Nicholas (Melbourne) gave results of an investigation into the validity of Matthiessen's rule for cold-worked metals and alloys and put forward a qualitative interpretation of the small deviations found.

Resistance changes due to the irradiation of pure metals and the ordered alloy $\mathrm{Cu}_{3} \mathrm{Au}$ by electrons, neutrons, deuterons, etc., were discussed by R. A. Dugdale (Harwell). As in deformation studies, recovery experiments reveal effects almost certainly due to the diffusion of vacancies, and indeed recent work at Harwell on $\mathrm{Cu}_{3} \mathrm{Au}$ has shown very similar activation energies for recovery of resistivity measured after irradiation, after quenching and after coldworking.

Dr. K. Lücke (Göttingen) reviewed the influence of impurities in copper on the results of deformation and recovery experiments and also gave an account of work on resistance changes in iron due to strainageing. Two contributed papers dealt with resistance changes in alloys: Dr. W. H. Aarts and R. K. Jarvis (Johannesburg) reported increases of resistivity during room-temperature annealing of some silver-gold alloys following deformation at low temperatures; Dr. J. O. Linde (Stockholm) wrote giving the results of a study of the effect of deformation on the resistivity of certain binary, ternary and quaternary alloys of silver and gold with transition metals. Finally, J. F. Nicholas (Melbourne) pointed out the lack of any direct experimental or theoretical evidence for the supposition that large resistivity changes caused by the deformation of some alloys are due to the destruction of short-range order.

Many interesting points were raised in discussion and served to reveal the utility of resistivity studies as a means of investigating the structure of metals.

'T' Broom

\section{CROSSED AMORPHOUS AND CRYSTALLINE CHAIN ORIENTATION IN POLYTHENE FILM}

By D. R. HOLMES, R. G. MILLER, R. P. PALMER and C. W. BUNN

Plastics Division, Imperial Chemical Industries, Ltd., Welwyn Garden City, Herts

THE structure of polythene film has been investigated by X-ray, optical and polarized infra-red methods. It was found that the polymer chains are oriented differently in the crystalline and the amorphous regions, the respective chain axes being perpendicular to each other. We are unaware of any previous investigations into the orientation in both crystalline and amorphous regions, and as a result this remarkable phenomenon has escaped notice.

Most polythene film is produced by extruding the viscous molten polymer through a slit, passing the resulting sheet downwards into a water quenchingbath, under an idler roller and finally on to a wind-up roller. The whole system is very nearly tensionless to prevent drawing of the film; nevertheless, the films produced do possess some orientation.

The samples available varied in thickness from $0.04 \mathrm{~mm}$. to $0.11 \mathrm{~mm}$. and proved to be of convenient thickness for all three experimental methods, and so no preparatory techniques which might have affected the molecular structure of the film were necessary. 